\title{
LA NOVELA POLICIACA DE QUIOSCO COMO NARRATIVA DE TERROR: VILLA DEL MAR Y EL CASERÓN DEL ÓRGANO DE JOSEFINA DE LA TORRE
}

THE CRIMINAL KIOSK NOVEL AS HORROR NARRATIVE: VILLA DEL MAR AND EL CASERÓN DEL ÓRGANO BY JOSEFINA DE LA TORRE

\author{
Alberto García-Aguilar \\ Universidad de La Laguna
}

\section{ABSTRACT}

This article analyses two kiosk novels published by the Spanish writer Josefina de la Torre during the decade of 1940: Villa del Mar (1941) and El caserón del órgano (1944). It studies how she reproduces in them some of the most common features of the crime and horror subgenres, such as the detective as an adventure hero, the (false) haunted house and the incredibly evil murderer, to offer works intended for the leisure of the readers ${ }^{1}$.

Key words: Crime novel, horror novel, popular literature, kiosk novel, Josefina de la Torre.

\footnotetext{
1 Trabajo cofinanciado por la Agencia Canaria de Investigación, Innovación y Sociedad de la Información de la Consejería de Economía, Industria, Comercio y Conocimiento y por el Fondo Social Europeo (FSE) Programa Operativo Integrado de Canarias 2014-2020, Eje 3 Tema Prioritario 74 (85\%).
} 


\section{RESUMEN}

Este artículo analiza dos novelas de quiosco publicadas en la década de 1940 por la escritora española Josefina de la Torre: Villa del Mar (1941) y El caserón del órgano (1944). Se estudia cómo reproduce en ellas varios de los rasgos más frecuentes en los subgéneros policiaco y de terror, sobre todo el detective como un héroe de aventuras, la (falsa) casa encantada y el asesino increíblemente malvado, para ofrecer unas obras destinadas al ocio de los lectores.

Palabras clave: Novela policiaca, novela de terror, literatura popular, novela de quiosco, Josefina de la Torre.

Fecha de recepción 22 de mayo de 2019.

Fecha de aceptación: 20 de junio de 2019.

Cómo citar: García-Aguilar, Alberto (2019), «La novela policiaca de quiosco como narrativa de terror: Villa del Mar y El caserón del órgano de Josefina de la Torre», en Actio Nova: Revista de Teoria de la Literatura y Literatura Comparada, 3: 95-122.

DOI: https://doi.org/10.15366/actionova2019.3.005 


\section{INTRODUCCIÓN}

Aunque Josefina de la Torre (Las Palmas de Gran Canaria, 1907- Madrid, 2002) es conocida sobre todo por su poesía y, en menor medida, por su actividad teatral y cinematográfica, su faceta como novelista popular -tanto de narrativa rosa como criminalha caído casi en el olvido. Ni siquiera la reivindicación actual de las labores artísticas e intelectuales desarrolladas por el grupo de mujeres vinculadas a la Generación del 27 conocidas como las Sinsombrero (a las que Josefina de la Torre pertenecía) - ha servido para recuperar las novelas de quiosco que esta autora publicó en los primeros años de posguerra. Con ello, queda manifiesto el rechazo generalizado hacia esta literatura desde el ámbito académico español, a pesar de que, de acuerdo con Rueda Laffond, «durante la última década se han multiplicado los estudios sobre la novela popular» (2015: 668). Aún existen numerosas reticencias respecto al análisis de esta narrativa, aunque desde finales de los sesenta investigadores como Barreiro (1969), Díez Borque (1972), Amorós (1974), Alemán Sainz (1975), Álvarez Barrientos y Rodríguez Sánchez de León (1997), Eguidazu (2008) y Charlo Ortiz-Repiso (2013) han defendido su inclusión en los estudios literarios no solo por su valor sociológico, sino también porque su estudio supone la revisión del canon y de la historia de la literatura predominantes. Así, proyectos digitales como los presentados por RomeroLópez y Bueren Gómez-Acebo, que proponen la creación de una base de datos de literatura de quiosco centrada en el primer tercio del siglo XX, buscan igualmente la configuración de un canon alternativo que recoja esta literatura de masas (Romero-López y Bueren Gómez, 2019: 84).

Pero, a pesar de estos posicionamientos a favor del análisis de la narrativa popular, el desdén que sufre propicia el desinterés hacia la misma incluso cuando sus autores han alcanzado cierto prestigio y reconocimiento en otros géneros, tal como sucede en el caso de Josefina de la Torre, reivindicada especialmente por su obra lírica. De hecho, aunque algunos trabajos sobre la escritora publicados hasta el momento nombran el título de estas novelas e indican en qué colección aparecieron, no desarrollan ningún estudio de las mismas. Con la excepción de un artículo de Soler Gallo (2016) sobre su novela rosa La rival de Julieta (1940), la obra de Josefina incluida en la colección «La Novela Ideal» (1938-1944) ${ }^{2}$, al igual que la

\footnotetext{
2 A pesar de que Tarancón Gimeno (2001: 340) indica que la colección finalizó su actividad en 1943, esta se
} extendió hasta 1944. 
única que publicó en la Editorial Océano -El caserón del órgano (1944)-, apenas ha obtenido atención por parte de la crítica literaria, incluso cuando investigadores como Godsland (2007: 2) y Vosburg (2011: 76) califican sus novelas policiacas como algunos de los primeros ejemplos de narrativa criminal escrita por mujeres durante la Guerra Civil y en los años inmediatos a ella. La bibliografía existente sobre Josefina de la Torre no indaga en estas narraciones, de manera que la información sobre ellas se limita a la mención de los títulos o de su colaboración en este proyecto editorial, tal como se aprecia en los trabajos de Reyes (2000: 20), Hernández Quintana (2001: 48-49), De Santiago Mulas (2002: 609), Charlo (2005: 251), Durán (2008: 87), Mederos (1999: 46; 2008: 15), Millares (2008: 63), Utrera Macías (2008: 233), Martín Fumero (2011: 342-343; 2019: 592), Martín Padilla (2015a; 2015b; 2015c: 13) y Balló (2016: 259). Reverón Alfonso aborda el tema con algo más de extensión, centrándose en el origen de la colección y en sus objetivos (2007: 216-220), al igual que Vázquez de Parga (1993: 99-100; 2000: 33), aunque ninguno de ellos analiza los textos. Otros estudiosos, como Lázaro Santana (1989) y Catherine G. Bellver (2001), ni siquiera aluden a estas obras: el primero, al nombrar las publicaciones narrativas de la autora, solo indica la novela corta Memorias de una estrella (1954) y el cuento que se incluyó en este mismo volumen, «En el umbral» (Santana, 1989: 21); la segunda, aunque se centra en sus textos líricos, no se refiere a su faceta como novelista en la breve semblanza biográfica que precede al análisis de sus poemas (Bellver, 2001: 84-86).

La escasa atención filológica hacia las novelas de la autora justifica un estudio detenido de esta faceta suya. Por eso, este artículo se centrará en las dos novelas policiacas que, a su vez, contienen rasgos idiosincráticos de la narrativa de terror: Villa del Mar (1941) y El caserón del órgano (1944). La combinación que presentan de tópicos de distintos subgéneros ${ }^{3}$ los convierte en textos peculiares en los que Josefina de la Torre, ateniéndose a los esquemas narrativos y a los personajes que mostraban las novelas criminales de quiosco durante la autarquía franquista, propone la resolución de una serie de delitos al mismo tiempo que suscita sentimientos de miedo a través de tramas macabras, temas cercanos a lo tabú y asesinos sangrientos que esconden una maldad inusitada.

Para ello, en este análisis, que intentará determinar qué tópicos policiacos existen en estas novelas, así como el empleo de procedimientos y rasgos propios de la literatura de

\footnotetext{
${ }^{3}$ Dada la confusión terminológica en torno al concepto de subgénero literario, en este trabajo se empleará con el sentido que le da el crítico Kurt Spang, quien entiende por tal las subdivisiones -en este caso temáticas- de las «formas de presentación literarias o géneros teóricos, es decir, la narrativa, la dramática y la lírica» (2000 [1993]: 18).
} 
terror, se recurrirá a las ediciones originales. En primer lugar, se estudiará la relación de Josefina de la Torre con la colección «La Novela Ideal» y el terror a lo largo de su trayectoria literaria para, a continuación, examinar los dos textos señalados. El estudio de los mismos establecerá el tipo de escenario en que se desarrolla la mayor parte de las tramas -la falsa casa encantada-, el modelo de detective que lleva a cabo las investigaciones pertinentes para resolver los crímenes y, por último, el carácter irracional de los delitos cometidos, que provoca en los lectores temor ante los hechos narrados.

\section{JOSEFINA DE LA TORRE Y LA LITERATURA DE QUIOSCO: LA COLECCIÓN «LA} NOVELA IDEAL»

Josefina de la Torre, que nació en 1907 en una familia acomodada y con numerosas figuras de relevancia cultural de Las Palmas de Gran Canaria, pronto desarrolló un gran interés hacia la literatura, hasta el punto de que desde su infancia, tal como señala Ryker (2008: 241), escribía poemas. Ya en 1927 publicó su primer poemario, Versos y estampas, acompañado por un prólogo de Pedro Salinas, y el siguiente, Poemas de la isla, apareció en 1930. Unos años después, en 1934, obtuvo uno de los principales reconocimientos por su obra lírica, que consistió en su inclusión en el libro Poesía española. Antología (Contemporáneos), preparado por Gerardo Diego, donde solo se recogen textos de dos mujeres: de ella y de Ernestina de Champourcín.

Si bien sigue escribiendo y publicando poesía durante la posguerra ${ }^{4}$, la dictadura franquista supone para ella un cambio significativo en el ámbito literario. El conflicto bélico, por las inclinaciones republicanas de su familia y de ella misma ${ }^{5}$, provocó en su familia ciertas dificultades personales y también económicas. Cuando estalló la guerra ella se encontraba en Madrid, y durante unos meses, desde agosto de 1936 hasta marzo de 1937 (Reverón Alfonso, 2007: 215), se refugió en la embajada de México de la capital. Cuando al fin regresó a comienzos del año siguiente a Las Palmas de Gran Canaria junto con su hermano Claudio

\footnotetext{
${ }^{4}$ Su tercer poemario, Marzo incompleto, conoció una primera edición en 1945 en la revista Fantasía (Martín Fumero, 2019: 586). Su segunda edición se publicó en formato de libro en 1968.

${ }^{5}$ Selena Millares afirma lo siguiente sobre el republicanismo de los familiares de la escritora: «Tampoco puede obviarse que Josefina de la Torre pertenecía a una familia de arraigada tradición republicana» (Millares, 2008: 65).
} 
de la Torre ${ }^{6}$, advirtió ciertos problemas pecuniarios en su familia causados por la guerra. Para afrontarlos, tanto Josefina como Claudio y su mujer -la también escritora Mercedes Ballesteros- fundan en Las Palmas ${ }^{7}$ la colección popular «La Novela Ideal», dedicada sobre todo a novela rosa y policiaca, subgéneros literarios que gozaban de éxito en el mercado editorial de esos años.

La elevada demanda de esta narrativa de masas durante la década de 1940 se debe en gran medida a la necesidad de evasión que existía en la posguerra por parte de los españoles, que vivían «en un país [...] sometido a durísimas condiciones materiales (son los años del hambre), y con el trauma de una reciente guerra y un clima político opresivo» (Eguidazu, 2008: 20). Este deseo de entretenimiento, junto con el formato económico de las novelas y la proliferación de quioscos - concebidos, según Alemán Sainz, como construcciones «de urgencia para la venta de publicaciones» (1975: 5)-, favorece su venta no solo entre el público con escasa formación cultural, como en ocasiones se piensa, sino también entre algunos lectores con un alto nivel educativo que a veces buscaban en la literatura un rato de ocio (Eguidazu, 2008: 23). Por ello, Claudio de la Torre, que ejercerá como editor de «La Novela Ideal», y Josefina de la Torre concluyen que, ante las limitaciones económicas por las que pasa su familia, afectada por el declive de la actividad comercial, la publicación de estas novelas proporcionará rápidos ingresos.

Esta colección se suma a aquellas de carácter popular que surgen en España durante esos años, entre las que Sánchez Zapatero y Martín Escribá (2011: 99) destacan las siguientes, dedicadas a la narrativa criminal: «Biblioteca Oro» (Editorial Molino), «Serie Wallace» (Editorial Cisne), «Colección Misterio» (Editorial Clíper) y «Biblioteca Iris» (Editorial Bruguera). Los escritores que trabajan para ellas no publican con pretensiones artísticas o con la intención de que sus textos perduren, pues las condiciones laborales que sufren tampoco se lo permiten. Bajo una presión considerable para satisfacer la constante demanda de una literatura de entretenimiento, no gozan del tiempo suficiente para desarrollar personajes complejos o tramas que inciten a la reflexión. Así, en la advertencia al lector del primer número de «La Novela Ideal», City Hotel-de Rocq Morris (pseudónimo de Mercedes

\footnotetext{
${ }^{6}$ Claudio de la Torre (Las Palmas de Gran Canaria, 1895 - Madrid, 1973), que desarrolló actividades como dramaturgo, narrador, director de cine y de teatro, periodista y guionista, ya había recibido importantes reconocimientos antes de la Guerra Civil, entre los que destaca el Premio Nacional de Literatura por su novela En la vida del señor Alegre (1924).

${ }^{7}$ A pesar de ser fundada en Las Palmas de Gran Canaria, a partir del año 1939 las narraciones de «La Novela Ideal» se publicarán en Madrid, en la imprenta de Gráficas Uguina.
} 
Ballesteros)-, publicado en septiembre de 1938, los editores señalan que estas obras buscan proporcionar un rato de ocio a sus compradores:

Éstas [novelas] se dirigen, sobre todo, a ese extenso mundo de lectores, ávidos de agradable solaz, de amena y fácil lectura, que, en la ajetreada actividad de nuestra vida nacional, no siempre encuentra a mano el libro interesante y económico, de cómodo formato, además, con que entretener el ocio fugaz de cada día (Reverón Alfonso, 2007: 216-217).

En esta colección Josefina de la Torre publica un total de diez narraciones: siete novelas $\operatorname{rosas}^{8} \mathrm{y}$ tres policiacas, que incluyen El enigma de los ojos grises (1938), Alarma en el Distrito Sur (1939) y Villa del Mar (1941) ${ }^{9}$. Todas ellas, sin embargo, aparecen firmadas con el pseudónimo de Laura de Cominges ${ }^{10}$, lo que resulta significativo sobre todo en sus obras policiacas, incluso cuando en este periodo se empleaban con frecuencia pseudónimos extranjeros o poco comunes en España para, como afirman Martín Escribá y Sánchez Zapatero, «dar verosimilitud a unas historias protagonizadas por extranjeros y en el extranjero» (2011: 99). Por un lado, al ocultar su identidad en estas novelas, que ella nunca apreció mucho por considerar que no presentaban demasiado interés literario (Checa, 1997), salvaguardaba en cierto modo el prestigio que había obtenido como poeta antes de la Guerra Civil. Y, por otro, al elegir un pseudónimo femenino reivindicaba su condición de mujer como novelista policiaca, algo no demasiado frecuente en esos años, cuando, en el ámbito de la literatura popular, el nombre de una mujer en la portada se asociaba más a una narrativa de carácter sentimental (sobre todo si, como ocurre en este caso, bajo ese mismo nombre también se habían publicado novelas rosas). De hecho, en esta misma colección, Mercedes Ballesteros emplea un pseudónimo masculino para sus novelas policiacas, Rocq Morris, y otro femenino para las rosas, Sylvia Visconti. Sin embargo, Josefina de la Torre firma en ambos casos con el mismo pseudónimo, resaltando así la autoría femenina de esta literatura criminal.

La escritora mantendrá el nombre de Laura de Cominges incluso cuando publica su última novela policiaca en otra colección, llamada «Inventos, Viajes, Misterios, Aventuras»,

\footnotetext{
${ }^{8}$ El conjunto de novelas rosas publicadas por Josefina de la Torre incluye las siguientes obras: María Victoria (1940), La rival de Julieta (1940), Matrimonio por sorpresa (1941), ¡Me casaré contigo! (1941), Tú eres él (1942), Idilio bajo el terror (1943) y ¿Dónde está mi marido? (1943).

${ }^{9}$ De estas tres novelas, El enigma de los ojos grises conoció una segunda edición en 1941 y Villa del Mar, en 1944. ${ }^{10} \mathrm{La}$ propia Josefina de la Torre, en una entrevista a Primer Plano, explica la elección de este pseudónimo: «Me puse Cominges porque es el segundo apellido de mi madre [sic], y Laura porque me gusta ese nombre» (Morales, 1943: 8). En realidad, el apellido referido pertenece a su padre.
} 
de Ediciones Océano. Según Vázquez de Parga (2000: 33), esta nueva editorial no contaba con originales suficientes, así que recurrió a algunos escritores de «La Novela Ideal», entre los que se encuentran Josefina de la Torre y Mercedes Ballesteros ${ }^{11}$, quienes escribieron una novela para ella. Ballesteros publica Cena siniestra (1944), protagonizada por un detective paródico sobre el que, por lo que indica el subtítulo -«Hazañas de Robert Clay»-, se pensó en desarrollar una serie literaria que, sin embargo, jamás se continuó ${ }^{12}$; y, por su parte, Josefina de la Torre publica su cuarta y última novela policiaca, El caserón del órgano (1944).

\subsection{EL TERROR EN LA NARRATIVA DE JOSEFINA DE LA TORRE}

A diferencia del subgénero policiaco, el de terror apenas existe entre las novelas de quiosco de los primeros años de posguerra. Ante la escasa demanda de este tipo de narraciones, casi no se cultivó por los escritores españoles porque, como sostiene Vázquez de Parga, «nunca el terror leído tuvo muchos adeptos en el país» (2000: 251). Charlo OrtizRepiso confirma estas apreciaciones en su estudio sobre novela popular española, donde explica que hasta 1945 no aparece en España una colección dedicada al subgénero, Fantástica, «subtitulada Magazine de historias, leyendas y relatos impresionantes» (2013: 212). Aunque se encuentran algunos títulos que remiten al terror, como «Las catacumbas de Londres, Arañas negras o Los camaradas de Satanás» (Charlo Ortiz-Repiso, 2013: 212), estos, de acuerdo con él, no constituyen verdaderos ejemplos de esta literatura, pues «todos ellos se deben de encuadrar en la novela popular policíaca» (Charlo Ortiz-Repiso, 2013: 212). Se advierte, por tanto, una estrecha relación entre la literatura criminal de quiosco y el terror, de manera que este último contribuye, en las narraciones policiacas, a crear la atmósfera amenazante y perturbadora en la que se desarrollan los crímenes y que inquieta a los lectores, tal como se observa en Villa del Mar y en El caserón del órgano.

No obstante, aunque el análisis desarrollado en este trabajo se centra en estas dos obras de Josefina de la Torre, la relación de la autora con la narrativa de terror no se limita a

\footnotetext{
11 Según Reverón Alfonso (2007: 220), Bernardo de la Torre, sobrino de Claudio y Josefina, también escribió para «La Novela Ideal», aunque no consta su nombre en ninguna obra de la colección. Sin embargo, en Ediciones Océanos sí aparecerá la novela Locura en la selva (1944), firmada por B. de la Torre.

12 En El caserón del órgano se publicita así: «Cena siniestra. Este es el título del primer episodio de la serie "Hazañas de Robert Clay"» (De la Torre, 1944: 72). Este anuncio ha podido confundir a estudiosos como Vázquez de Parga (1993: 100), quien afirma por error que Robert Clay protagoniza las cuatro novelas policiacas publicadas bajo el nombre de Rocq Morris, cuando en realidad solo interviene en Cena siniestra.
} 
ellas, ya que mostró su interés por este subgénero en otros textos publicados con posterioridad. A él pertenecen también dos cuentos suyos: «En el umbral», incluido en el mismo volumen que su novela Memorias de una estrella (1954); y «Un corazón constante» ${ }^{13}$, publicado en 1990 en el número 23/24 de la revista Alor Novísimo, que, según Carlos Reyes, «nos hace recordar a Edgar Allan Poe» (2001: 7). En el primero de ellos se narra el trágico encuentro de un hombre misterioso con el protagonista, quien cuenta en primera persona las diversas desgracias que ese ser, una suerte de ente maligno, atrae hacia él, incluyendo el atropello mortal de su hijo. Por otro lado, «Un corazón constante» narra, en dos páginas, cómo un hombre se queda con el corazón de su pareja, recién fallecida a causa de un atropello, y lo conserva en una urna de cristal. Sin embargo, al poco tiempo surgen del órgano pequeñas ramas que crecen hasta cobrar vida propia y asfixiar al protagonista, a quien encuentran muerto sobre una mesa.

Con estas publicaciones, en las que el terror se manifiesta a través de hechos de naturaleza sobrenatural, Josefina de la Torre demuestra que su interés por este subgénero, si bien quedó expresado en pocos textos suyos, no se redujo a la novela popular. El hecho de que escribiera cuentos de terror décadas después de su participación en «La Novela Ideal» prueba que este subgénero suscitaba su curiosidad y que, más allá de las narraciones de quiosco, resultaba en ocasiones el subgénero adecuado para expresar sus inquietudes literarias.

\section{LA FALSA CASA ENCANTADA COMO ESCENARIO DEL CRIMEN}

La combinación en la novela policiaca de características y tópicos idiosincráticos de diversos subgéneros constituye un procedimiento común en la literatura popular. A este respecto, resulta esclarecedora la explicación de Martín Cerezo:

Los subgéneros literarios se definen por sus características referenciales. Este es el caso, por ejemplo, del subgénero policiaco, cuya esencia es la presencia en su estructura de conjunto referencial de un crimen (o la apariencia del mismo) y su investigación. El subgénero policiaco, según Javier Rodríguez Pequeño, se define exclusivamente por una acción (un crimen) y un proceso (la investigación de ese crimen); toda obra que posea estos elementos será considerada policiaca, si bien puede cumplir también las características de otro subgénero (2006: 21).

${ }_{13}$ Recogido luego por Carlos Reyes en la antología bilingüe Hojas sueltas (2001), donde seleccionó (y tradujo al inglés) cinco textos breves de Josefina de la Torre publicados en las revistas Capela y Alor Novísimo. 
Por eso, «es manifiesto para cualquier lector medio que en ocasiones [...] se produce una confluencia estrecha entre lo terrorífico, las aventuras y lo policiaco» (Martín Cerezo, 2006: 38), tal como sucede en Villa del Mary en El caserón del órgano, donde precisamente estos tres subgéneros se combinan para ofrecer una historia que se ajusta a los patrones narrativos de la literatura criminal en los años de la autarquía franquista. De este modo, la narración de una serie de crímenes y su correspondiente investigación por parte de policías profesionales y de personajes con espíritu detectivesco presenta rasgos del subgénero del terror ya incluso desde el título de El caserón del órgano, que remite a uno de los espacios más recurrentes de este subgénero: la mansión (aparentemente) encantada. También en la ilustración de la portada destaca este espacio: en ella se aprecia en primer plano a una mujer vestida para una fiesta de gala que huye asustada de una tétrica mansión que se observa al fondo. Y, aunque la plácida portada de Villa del Mar, con una joven rubia que se apoya con suavidad en un caballo, parece más propia de una novela rosa que de una policiaca, el título de esta obra se refiere igualmente al espacio donde se cometen los crímenes: una opulenta villa, perteneciente a la aristocrática familia Maxen Winiard, en la que una joven recién contratada como ama de llaves advierte ciertos misterios y comportamientos que no comprende.

Estas viviendas se sitúan, en ambas novelas, en una ciudad extranjera, lo que responde a las circunstancias sociopolíticas de este periodo. Las leyes de la dictadura prohibían que los detectives privados participaran en la resolución de asesinatos y, además, resultaba imposible describir crímenes ocurridos en territorio español, pues, como explican Martín Escribá y Sánchez Zapatero, «su sola mención podía ser interpretada como una muestra de debilidad del régimen» (2011: 99). Esta férrea censura también condicionaba el enfoque con el que se presentaban los crímenes y los grupos humanos en los que se cometían, ya que, para evitar una crítica social que ocasionara problemas con las instituciones franquistas, los autores no adaptaban los cánones de la novela negra, sino «los modelos policiacos [que] acostumbraban a presentar una sociedad exótica y alejada del país» (Sánchez Zapatero, 2006: 74). Para intensificar la evasión que buscan los lectores, los personajes de estas novelas pertenecen muchas veces a la clase alta o a la nobleza, de modo que el ambiente con el que interactúan le resulta aún más lejano al público lector. Todos ellos, con un considerable poder adquisitivo, exhiben el lujo del que disfrutan en diversas ocasiones. Así, en El caserón del órgano una de las mujeres exhibe un «pendantif [sic] de brillantes que descansaba en su pecho» (De la Torre, 1944: 3), mientras que la mansión de Villa del Mar, en 
manos de una baronesa, presenta un «amplio vestíbulo, de cuyos muros colgaban valiosos tapices y curiosas panoplias. Una ancha escalera central ocupaba gran parte del testero principal» (De la Torre, 1941: 11). De este modo, se publican textos que, aunque proceden de autores españoles, no constituyen una literatura propiamente española al eludir tanto escenarios localizados en el país como cuestiones socioculturales relacionadas con el mismo.

En este caso, la acción de las novelas se desarrolla en Inglaterra: en Villa del Mar, en un pueblo llamado Rivery; en El caserón del órgano, a las afueras de Londres. No obstante, la mayor parte de la trama transcurre en el interior de las viviendas aludidas en los títulos, que constituyen falsas mansiones encantadas, es decir, casas en las que hechos en apariencia sobrenaturales poseen una explicación lógica. Se trata de espacios que, tal como explica Gómez Rivero, se emplean con frecuencia en la literatura criminal, pues conforman un «marco ideal para tramas policíacas con intereses ocultos disfrazados de fantástico» (2007: 14). Lo explicable se presenta como irracional para producir un efecto de terror más intenso en los lectores y despertar sus miedos ante lo desconocido.

En Villa del Mar, este carácter fantasmal de la vivienda se sugiere desde el comienzo, cuando un tenebroso mayordomo ofrece a la protagonista, Hellen Preston, trabajar en la villa homónima como ama de llaves. Este personaje que la contrata, el mayordomo Emil, vaticina con su inquietante aspecto los extraños acontecimientos que la joven presenciará: «Por el cuello del gabán enlutado que le cubría todo el cuerpo asomaba un rostro pálido, inexpresivo, en cuyos ojos brillaba como una chispa eléctrica» (De la Torre, 1941: 7). Dado que se encuentra sin trabajo, Hellen acepta, pero durante el recorrido hacia la mansión experimenta cierto miedo al observar lo aislada que se encuentra la mansión, bastante lejos del pueblo más cercano y justo al lado de un imponente acantilado: «El corazón dejó de latirle unos segundos. Bordeaban un abrupto precipicio que se perdía en la oscuridad y, allá en su fondo, brillaba una extensa superficie que Hellen no dudó se trataba [sic] del mar» (De la Torre, 1941: 7). Ni siquiera el momento de entrar a la mansión queda desprovisto de intranquilidad, pues, si bien nada en la fachada resulta llamativo, «el viento, implacable, la empujaba por la espalda, según avanzaba hacia la puerta» (De la Torre, 1941: 10).

Ya instalada, numerosos acontecimientos sugieren que una suerte de maldición castiga a los habitantes de la lujosa villa, y Hellen concluye que «algo debía ocurrir sin duda en aquella casa» (De la Torre, 1941: 10). No solo la obsesiva preocupación de la dueña de la mansión, la baronesa Maxen Winiard, por su hija Eva -tetrapléjica y en silla de ruedasresulta extraña, hasta el punto de que prohíbe que nadie traspase la galería de ventanas góticas 
por la que se accede a sus habitaciones. De hecho, Hellen sirve como ama de llaves porque la baronesa «no puede abandonar a su hija» (De la Torre, 1941: 6). Pero ese hechizo sobrenatural y malévolo que, por lo que observa, afecta a los habitantes de la vivienda también se extiende a los animales, de manera que, según la baronesa, la yegua que montaba Eva cuando sufrió el accidente que la dejó paralítica «parece embrujada» (De la Torre, 1941: $35)$.

Del mismo modo, en El caserón del órgano suceden hechos difíciles de explicar en la mansión a la que Federico Weldom, un prestigioso organista, se ha mudado. En contraste con el carácter «muy comunicativo y alegre» (De la Torre, 1944: 4) que había mostrado hasta adquirir la casa, su creciente obsesión con el órgano del que allí disfruta sugieren un ambiente opresivo, donde la locura, acaso causada por ese viejo caserón, cambia la personalidad social del músico por otra retraída y solitaria. Aislado en su nueva propiedad, vive solo y sin criados, con un único cocinero a su servicio.

Desde las primeras páginas de la novela se aprecia lo que Carrera Garrido denomina retórica del terror, esto es, un léxico tenebroso y reminiscente de los tópicos del subgénero que se expresan en un estilo «donde las descripciones están al servicio de la atmósfera» (2015: 83). Así, para sugerir una supuesta maldición, se presenta la vivienda de Weldom como una «endiablada casa» (De la Torre, 1944: 2) donde las «sombras se mezclaban con las telarañas» (De la Torre, 1944: 4). Además, una de las amigas del organista, Myrna, extrañada por la continua ausencia del organista en sus reuniones con el resto del grupo durante los últimos meses, afirma que en esa nueva mansión a «Weldom sólo le retienen los fantasmas» (De la Torre, 1944: 3). Por eso, cuando Mrs. Field, una de sus amistades, plantea la posibilidad de visitarlo para animarle, Myrna expresa su temor: «زYo no me meto en esa casa encantada!» (De la Torre, 1944: 4).

Como casi ninguno de estos amigos cree en una verdadera maldición, toman la decisión de visitar a Federico durante las vacaciones de Navidad. No obstante, a medida que se acercan a la vivienda del organista advierten una atmósfera inquietante que vaticina un espacio terrorífico. Sin ser conscientes de ello, al dirigirse al caserón traspasan una suerte de umbral que separa el ámbito cotidiano del mundo del crimen al que se dirigen, tal como denota la niebla «cada vez más densa» (De la Torre, 1944: 7) que envuelve el coche que conducen. Ya frente a la vivienda, al igual que en Villa del Mar, sienten un inesperado viento frío que despeja la niebla y observan que «nada en torno a [la casa] daba señales de vida» (De la Torre, 1944: 8). Los detalles siniestros continúan al entrar en la residencia de Federico, 
donde Howard Norton afirma, mirando al techo, que «había visto moverse algo ... allá arriba» (De la Torre, 1944: 9).

El aspecto del anfitrión también suscita temor a sus amigos. La dificultad en reconocerlo revela que su físico ha sufrido cambios importantes que lo han convertido en una figura fantasmagórica. Mary Davison concluye que «algo mortal y terrible debía invadirle [...]. En poco tiempo se había avejentado y su delgadez daba espanto» (De la Torre, 1944: 11). A esto se le une un comportamiento extraño durante la visita, pues, sin que los demás sepan por qué, toca el órgano a horas inusuales, cuando piensa que se encuentra solo en el caserón, y se halla en un casi constante estado de irritabilidad. El propio Federico contribuye a este miedo que experimentan varios de sus huéspedes cuando, durante una sincera conversación que mantiene con Mary, le advierte del peligro que existe en esa casa. Por lo que se deduce de sus palabras, este consiste en una maldición: «Sobre este caserón hay una amenaza que puede recaer sobre todos. La menor indiscreción haría que se cumpliera [...] Estoy desesperado, al borde de la locura» (De la Torre, 1944: 21).

Díez Borque, al relacionar la novela policiaca con el terror, afirma que algunas de estas obras crean una «transposición ilusoria de las amenazas» (1972: 120) desde el mundo ficticio al del lector para atemorizarle y transmitirle una angustia que, sin embargo, se alivia con el final de la investigación y el consecuente castigo a los criminales. Una de las técnicas empleadas para propiciar este sentimiento consiste en la elipsis, a la que el narrador omnisciente de El caserón del órgano recurre para privar al lector del resto de la información que Weldom le transmite a Mary en esa conversación sobre lo que ocurre en la vivienda. La charla entre ellos, donde Weldom le explica la verdad, queda interrumpida. Sin conocer lo que oculta el organista, hasta el momento todo indica que algún malvado hechizo existe en el caserón y provoca situaciones inexplicables, tal como comprueba Mary durante este encuentro con el músico cuando se percata de que «una de las caretas de la pared tenía los ojos brillantes, como vivos, que la miraban atrozmente» (De la Torre, 1944: 23). Sin embargo, las conclusiones posteriores del investigador ocupado del caso acabarán con estas primeras impresiones, descubriendo la explicación lógica que desmonta la aparente maldición que pende sobre ellos. 


\section{El DETECTIVE, UN HÉROE DE AVENTURAS POLICIACAS}

La novela policiaca de la década de los años cuarenta exigía un detective que solucionara los crímenes no solo gracias a sus capacidades de deducción, sino sobre todo por su actitud activa en la búsqueda de pruebas o en el enfrentamiento con los delincuentes, incluso ejerciendo la violencia si así lo requiriera la situación. Con ello se alcanzaba un público lector más amplio, ya que, como explica Dennis Porter, «the detective fiction of pure ratiocination $[. .$.$] has never been genuinely popular. In order to appeal to a broader public,$ it needed the vital admixture of action or manners, violence or satire» (1983: 163).

Este gusto por los detectives heroicos resultaba compatible con la considerable velocidad con la que escribían los autores de estas narraciones de quiosco, ya que el ritmo a menudo frenético de redacción les impedía desarrollar tramas policiacas en las que la resolución de los delitos dependiera de una compleja reflexión intelectual. Por eso, la publicación constante de novelas «para contrarrestar la escasa remuneración percibida» (Colmeiro, 1994: 138) provoca que estos escritores recurran a investigadores que resuelven los crímenes gracias a su personalidad aventurera y, por tanto, a su participación en persecuciones, espionajes, exploraciones de lugares sospechosos, peleas con los criminales y detenciones ejercidas por ellos mismos. En cierto modo, este tipo de detective supone una continuación de la novela de aventuras delictivas, que surge en España cuando, antes de la Guerra Civil, «la editorial Molino publica su colección de "Hombres Audaces”, copia de los pulps norteamericanos dedicados íntegramente a la narración de aventuras criminales de personajes como La Sombra, Doc Savage [...]» (Valles Calatrava, 1991: 97). A este modelo de investigador, que aúna notables habilidades tanto físicas como mentales (aunque no siempre exhiba estas últimas), además de una enorme valentía y un indiscutible sentido de la justicia, responden los detectives profesionales encargados de resolver los enigmas planteados en Villa del Mar y en El caserón del órgano.

No obstante, otros personajes que no pertenecen a ningún cuerpo policial también ayudan en la resolución de los casos. Así, en la primera de estas obras Hellen, ante los diversos misterios que observa en la villa y tras la información que le proporciona su antigua patrona, quien le cuenta que muchos piensan que la baronesa ha embalsamado el cadáver de su hija, manifiesta su intención de colaborar con los agentes oficiales: «No sería la primera vez que una mujer prestara un buen servicio a la policía» (De la Torre, 1941: 37). Incluso, 
cuando avanza en sus inquisiciones, se compara con uno de los grandes detectives literarios: «Se sentía casi un Sherlock Holmes» (De la Torre, 1941: 57).

Ni siquiera cuando pasa sus vacaciones en el Strand Hotel, en el pueblo vecino de Daisy-Vallee, abandona este espíritu detectivesco. Cuando se da cuenta de que en el mismo hotel se aloja un hombre desconocido que ha visto en la caseta del jardinero de la villa, realiza nuevas indagaciones para identificarlo. Tras descubrir su nombre-Albert Deblanc-, trata de averiguar el porqué de su extraña actitud y de la vigilancia que ejerce sobre el hermano de Eva, Harry, quien juega en el casino del establecimiento. La muerte de la baronesa, sin embargo, interrumpe sus vacaciones y su investigación particular.

De vuelta a la mansión, Harry, entristecido por el fallecimiento de su madre, le revela lo que ha descubierto tras el fallecimiento de su madre: su hermana Eva lleva años muerta y su madre ha cuidado de su cadáver embalsamado (De la Torre, 1941: 69). Así, el rumor que circulaba por el pueblo se revela como cierto, pero no gracias a deducciones ni al cotejo de pruebas, sino a la muerte de la baronesa, es decir, a un hecho casual. Con este secreto descubierto, solo queda un último enigma por resolver: dónde se encuentra el doctor Labusse, el que llevó a cabo el embalsamiento de Eva.

La llegada posterior a la villa de un grupo de agentes, conformado por el jefe de la policía y dos oficiales, supone el fin de la investigación profesional. Pero, una vez más, los enigmas no se esclarecen gracias a las capacidades deductivas de nadie, sino, en este caso, por el espionaje que un policía ha realizado sobre la familia Maxen Winiard. El mayordomo Emil, ante la sorpresa de Hellen, se convierte en Albert Deblanc tras desprenderse de su disfraz. En realidad, se trata de Albert Anderson, a quien el jefe de policía describe como «el mejor detective de nuestro tiempo» (De la Torre, 1941: 94). Su procedimiento de investigación, sin embargo, dista mucho del de un intelectual. Cuando, tras la muerte de Eva y su embalsamiento, la baronesa y Harry despidieron a todo el servicio y contrataron a nuevos trabajadores, Anderson entró oculto bajo la identidad de Emil. Así espió todo cuanto ocurría en la mansión.

El misterio, por tanto, queda resuelto gracias a su astucia. Harry, que sentía unos celos terribles de su hermana por acaparar toda la atención de su madre, ideó un plan para deshacerse de ella que consistía en provocar que Eva cayera de su yegua cuando cabalgaba por el bosque. Como había planeado, Eva quedó malherida y agonizando, pero, aun así, Harry le prometió a su madre que, si le dejaba la baronía y su fortuna como herencia, no la separaría de Eva. Ella aceptó. Pero, cuando su hermana murió, la única opción que le 
quedaba para mantenerla junto con su madre consistía en embalsamarla, de lo que se encargó el doctor Labusse. Su detención, que se produce cuando intenta huir del país, supone ese «orgasmo final del éxito del héroe» que, como explica Vázquez Montalbán (1989: 50), caracterizaba estas novelas policiacas de quiosco.

Esta táctica de espionaje, aunque no requiere ninguna violencia por parte del detective, resulta útil para averiguar todo lo sucedido y descubrir hasta qué punto llega la maldad de Harry, cuya falta de escrúpulos no se limita a este crimen, sino que también abarca la muerte de su madre. Una noche en el casino, en la que dio rienda suelta a su ludopatía, perdió una considerable cantidad de dinero y, al pedirle al día siguiente más a su madre, ella se negó. Pero, en un forcejeo entre ambos, la baronesa cayó y se golpeó la cabeza contra la esquina de un mueble, muriendo en el acto. Harry, entonces, simuló no conocer la verdad sobre su hermana, pues, si la hubiera reconocido, habría perdido la herencia.

El detective de El caserón del órgano, Peter Bley, sigue unos procedimientos similares a los de Albert Anderson en su investigación, incluyendo el espionaje y la ocultación de su verdadera identidad. Aunque, en este caso, realiza algunas sencillas deducciones que facilitan el esclarecimiento del enigma. Si bien estas reflexiones no revelan una sorprendente capacidad deductiva, la reacción de los personajes cuando descubren que tras el nombre falso de Peter Bley se esconde el prestigioso detective Jack C. Brown, miembro de Scotland Yard, demuestra que su trayectoria profesional lo avala como un gran investigador. Cuando muestra su nombre real al enseñar su ficha acreditativa, todos callan y le miran sorprendidos: «Un silencio siguió a esta lectura, y Carter alzó tímidamente la cabeza para mirar al dueño de aquella famosa ficha tan popular en el mundo policiaco» (De la Torre, 1944: 60).

También en esta novela varios personajes que no pertenecen a ningún cuerpo policial colaboran en la resolución del misterio, sobre todo Howard Norton, uno de los amigos de Federico. Al igual que la joven protagonista de Villa del Mar, Howard no duda en explorar la habitación donde Mary ha sido hallada muerta - poco después de que supuestamente le haya caído una rama mientras paseaba-, y tampoco se acobarda ante los aparentes peligros: «Estaba decidido a esclarecer el misterio aquella noche, y no se acostaría hasta haberlo conseguido» (De la Torre, 1944: 52). También Jessie Andrew, secretaria de Peter Bley, muestra una actitud detectivesca, sobre todo tras la llegada al caserón de Gracián Alvear, hijo del antiguo dueño de la vivienda. La inquietud que este personaje le transmite la lleva a recabar pruebas de cualquier tipo que aclaren su situación. Piensa, como Howard, en resolver cuanto antes el misterio, lo que demuestra su profesionalidad como investigadora: «Su cabeza 
trabajaba con ideas encontradas y deseaba ardientemente hallarles la solución» (De la Torre, 1944: 43). Todos los riesgos, a pesar del peligro que suponen para su propia integridad física, quedan justificados por el deseo de ambos de ayudar a los que conviven en el caserón y evitar la amenaza que, según todo indica, se cierne sobre ellos, tal como Norton explica: «Yo sólo trato de ayudarte y de librar a todos los que vivimos bajo este techo de un peligro que estoy seguro que existe» (De la Torre, 1944: 48).

No obstante, el responsable oficial del caso, Jack C. Brown, infiltrado en la mansión como un conocido de uno de los amigos de Federico Weldom, relaciona distintas pruebas que le conducen a reflexiones significativas. Así se da cuenta de que las huellas que aparecieron en el despacho de un notario -Veragüas-, asesinado con anterioridad a la visita al caserón, no pertenecían a un niño, sino a un adulto con algún tipo de discapacidad física: «QQué clase de deformidad física era la que padecía su desgraciado discípulo? ¿Y no era por casualidad el notario Veragüas el depositario del testamento de Sebastián Alvear?» (De la Torre, 1944: 61). Asimismo, resalta el hecho de que tres mujeres relacionadas con Federico y ya fallecidas -dos antiguas amantes suyas y Mary Davison- presentaban una mancha sospechosa en la sien.

La resolución del caso, sin embargo, se logra por el procedimiento más sencillo de todos: la confesión del criminal. Federico Weldom, acorralado por los datos que Brown expone, reconoce que él ha asesinado a esas tres mujeres por un impulso incapaz de controlar hacia las sienes palpitantes y pálidas de esas jóvenes. Asimismo, los asesinatos del notario Veragüas y de Gracián Alvear han sido cometidos por el hermano de este último, Jerónimo Alvear, un jorobado que vive en el caserón de Weldom. Para apresarlo, Brown recurre a cierta violencia contra el organista, quien sabe el lugar de la vivienda donde se encuentra: «Empujó a Weldom por la espalda con el cañón de la pistola» (De la Torre, 1944: 63).

Jerónimo, al igual que Federico, confiesa sus crímenes y soluciona el enigma relacionado con el «robo de una famosa perla oriental y de la esmeralda "Verdinna"» (De la Torre, 1944: 63). En este caso, la casualidad también ha desempeñado un papel importante en su resolución, ya que, como el propio Bley admite, las joyas se recuperaron «gracias al encuentro casual» (De la Torre, 1944: 63) de unas latas de sardinas que las contenían. Jerónimo cuenta que él había robado esas joyas del Museo del Cairo, donde su padre las había donado, porque, según su criterio, le pertenecen. Su padre, Sebastián Alvear -el antiguo dueño del caserón-, le había desheredado injustamente por sus deformidades, favoreciendo así a su hermano Gracián. Por eso, como venganza, asesinó al notario Veragüas, quien 
custodiaba el testamento de su padre, y a Gracián. Tras haber robado las joyas y el testamento, Jerónimo regresó al viejo caserón de su padre para ocultarse de todos. Como Federico ya habitaba en él, lo chantajeó al descubrir -de nuevo casualmente-su diario, donde narraba los crímenes que había cometido contra mujeres: si el organista le delataba, él también le entregaría a la policía.

Con la identificación de los criminales, llevada a cabo en ambas novelas tras espiar a los sospechosos y el lugar de los crímenes, culminan las investigaciones policiales. De este modo, al introducirse en el mundo de los asesinos para descubrir sus delitos, los detectives y los personajes que realizan pesquisas particulares se enfrentan a obstáculos que desembocan a veces en situaciones peligrosas para sus propias vidas. El misterio inherente a la historia policiaca queda así ligado al riesgo y a la acción que, como afirma Charlo Ortiz-Repiso, caracteriza las novelas de aventuras (2013: 178). El desenlace heroico llega gracias a la concatenación de algunas casualidades y, sobre todo, a la observación atenta y al espíritu aventurero de los investigadores -oficiales o no-, dispuestos a arriesgar su integridad física y a recurrir a la violencia.

\section{EL TERROR DE LOS CRÍMENES IRRACIONALES}

De acuerdo con la terminología empleada por Carroll ${ }^{14}$, las novelas aquí analizadas pertenecen al subgénero del terror -y no del horror-, ya que no existen monstruos de origen fantástico, sino varios criminales que presentan «abnormal psycholohies» (Carroll, 1990: 15). Así, el sentimiento de miedo se inspira en estas narraciones a través sobre todo del comportamiento de los asesinos, de las actitudes extrañas de algunos personajes y de la locura y la maldad exacerbada que muestran. Por ello, a pesar de que, solucionados todos los enigmas, se descubre que no existen acontecimientos sobrenaturales ni maldiciones mágicas en ninguna de las casas donde transcurren las tramas, el terror que transmiten corresponde a la que López Santana denomina tendencia irracional (2010: 238). En su estudio sobre la literatura gótica española, la investigadora determina que el carácter irracional de la narración de terror no se manifiesta solo a través de lo sobrenatural o de lo fantástico, sino «también

\footnotetext{
${ }^{14}$ Carroll distingue entre el concepto de terror y el de horror. Este último se diferencia del primero por la presencia
} de monstruos fantásticos o sobrenaturales (Carroll, 1990: 15). 
en todo aquello que, aun siendo real y tangible, traspasa los confines de lo permitido, de lo aceptable, de lo asumible socialmente» (López Santana, 2010: 238).

En Villa del Mar, el comportamiento de la baronesa y de Harry transgreden ampliamente estos límites, hasta el punto de que el engaño en el que participan resulta perturbador por la cercanía familiar de los delincuentes con la víctima. De esta manera, el joven heredero, aunque ha urdido el plan en el que se embalsamó el cadáver de su hermana, califica a su madre como una loca cuando, tras su muerte, finge que no conocía la realidad: «Ella la ocultaba porque no podía mostrarla a los demás, porque su locura había ido demasiado lejos...» (De la Torre, 1941: 69). Consciente de la dimensión del delito cometido, él mismo advierte lo execrable, lo monstruoso, que resulta para los demás el haber tratado el cadáver de Eva como si continuara viva. Por eso, aún sin reconocer su culpa, presenta a la baronesa como una madre cruel: «iNos ha burlado a todos, a mí, su único hijo, con la monstruosidad que forjó para consuelo suyo! ¡Es ella, mi hermana muerta!» (De la Torre, 1941: 69).

El temor suscitado por la novela proviene también de los extraños comportamientos que Hellen advierte en la villa de los Maxen Winiard, pues las actitudes sospechosas de la familia y de algunos miembros del servicio, por lo que todo indica, ocultan algún oscuro secreto. Existen varios momentos en los que la joven ama de llaves percibe algo extraño en sus conductas, y esta desconfianza queda justificada cuando sorprende a la baronesa en un momento tranquilo en el que le lee a Eva un libro. A pesar de que no observa nada anormal, la baronesa entra en cólera y le exige a Hellen que las deje solas. Harry, al enterarse de lo sucedido, muestra un interés demasiado evidente en conocer los detalles que la joven observó: «Hellen no acertaba aún a explicarse por qué el barón Maxen Winiard se había desconcertado tanto en aquel instante, ni por qué le había hecho relatar con minuciosidad lo ocurrido» (De la Torre, 1941: 20).

Los comportamientos inexplicables también se advierten cuando Hellen cabalga la yegua de Eva con su traje de jinete, provocando miedo en muchos que la ven. Nada más abandonar la villa, la joven escucha «un grito lejano, ahogado prontamente» (De la Torre, 1941: 27), y los habitantes del pueblo al que llega también expresan su temor, suscitado sin duda por los rumores que circulan entre ellos sobre el verdadero estado de la hija de la baronesa. Esta visión, que los vecinos creen fantasmal, les causa un impacto que la joven advierte casi de inmediato: «Al principio no le chocó que la mirasen tanto los campesinos que encontró al paso. Pero, una vez dentro del pueblo, le sorprendieron desagradablemente 
las miradas atónitas de los vecinos, observando cómo alguna mujer se santiguaba» (De la Torre, 1941: 29). Aunque las explicaciones lógicas ofrecidas por el detective Albert Anderson al final de la novela demuestran que nada de lo ocurrido proviene del mundo sobrenatural, las dudas suscitadas a lo largo del texto sobre esta cuestión, así como la desesperación cercana a la locura de la baronesa y la crueldad psicopática de Harry, convierten la narración en una historia que, sin contener seres mágicos, presenta un terror irracional.

Esta misma tendencia se aprecia El caserón del órgano. Aunque no intervienen monstruos fantásticos, Weldom, tanto por su aspecto demacrado como por sus delitos, remite a la figura del vampiro. Al quedarse a solas con Jessie, su manera de atacarle, mordiendo su cuello (De la Torre, 1944: 52), recuerda el comportamiento de estos seres, tal como confirman las apreciaciones de Norton al examinar los daños que el organista le ha causado a la joven: «Howard acababa de descubrir en el cuello de Jessie una mancha amoratada, llena de puntitos rojos. [...] Jessie tenía en la sien la misma mancha que en el cuello» (De la Torre, 1944: 52).

También otro de los personajes, Jerónimo Alvear, posee un aspecto que provoca en quienes lo contemplan un sentimiento inmediato de rechazo similar al que les produciría una criatura horrenda. De hecho, Norton, cuando lo ve por primera vez, piensa de su rostro que «[era el] del más repugnante ser humano, si así podía llamársele» (De la Torre, 1944: 34); del mismo modo, el narrador lo califica como un «monstruo» (De la Torre, 1944: 34). Esta prosopografía negativa del delincuente, como se aprecia con frecuencia en la literatura de terror -sobre todo en la de carácter más popular-, denota una naturaleza cruel o malvada en quien posee dicho aspecto. Con ello, el lector distingue con facilidad a los antagonistas de los héroes (excepto cuando un físico atractivo funciona como una máscara que oculta su personalidad malévola, o viceversa). De este modo, el jorobado presenta una serie de deformidades que, en efecto, constituyen el reflejo físico de su instinto criminal, de los sangrientos delitos que ha cometido: «Aquella forma siguió avanzando y, según se acercaba, vieron que se trataba de un ser deforme y jorobado, que a la escasa luz que reinaba presentaba un aspecto alucinante» (De la Torre, 1944: 65).

Esta maldad se manifiesta no solo en las muertes que ha provocado, sino también en la amenaza que pende sobre la vivienda del organista y a la que su dueño ha aludido en diversas ocasiones, sugiriendo algún tipo de maldición. No obstante, al final se revela como un peligro lógico que proviene del sistema de explosivos que el jorobado ha preparado en la mina bajo el caserón para, en caso de ser descubierto, derruirlo, tal como ocurre tras confesar 
sus crímenes. Justo después de haber esclarecido los hechos en el salón, los personajes escuchan unos rumores extraños que, poco a poco, aumentan de intensidad al mismo tiempo que Jerónimo Alvear adopta «una sonrisa estúpida» (De la Torre, 1944: 71) que evidencia su crueldad y su escasa cordura. Al darse todos cuenta de que, como había planeado el jorobado, la mansión va a caer sobre sí misma, huyen dejando atrás a los dos asesinos, cada uno con una actitud bien distinta ante su muerte inminente. Federico pide a gritos ayuda para escapar, mientras que Jerónimo, como un ser diabólico, emite «una carcajada continua» (De la Torre, 1944: 71) que confirma lo que sus deformidades señalan: su perversidad no conoce límites.

$\mathrm{Al}$ final el caserón, como todos esperaban, queda reducido a escombros: «Al fondo, donde antes se hallaba el caserón, había ahora unas ruinas amontonadas que alzaban el esqueleto de sus paredes con las ventanas abiertas sobre el cielo...» (De la Torre, 1944: 72). Este desenlace, que constituye una referencia intertextual implícita al cuento de Edgar Allan Poe «La caída de la Casa Usher» (1839) -donde la mansión familiar de los tétricos hermanos Usher cae derruida con ellos dentro durante una tormenta-, supone el restablecimiento del orden inicial. Aunque el detective Brown se siente desconsolado por no haber llevado ante la ley a los criminales, ha cumplido su objetivo: el caso ha sido resuelto, los asesinos han muerto y, con ello, han recibido su castigo. El lector contempla satisfecho el triunfo del bien y de la justicia sobre los crímenes sangrientos y la crueldad de los culpables.

Josefina de la Torre, por tanto, lleva a todos estos criminales a los límites de lo razonable para mostrar hasta qué punto llegan los impulsos más oscuros del ser humano. La incorporación de rasgos de la literatura de terror a la novela policiaca consigue unas historias en las que, en su aparente banalidad, se tratan algunas de las facetas más inquietantes de la psique humana. Las explicaciones lógicas a lo que en principio carecía de ellas no anula el terror macabro de los asesinatos cometidos por Federico Weldom ni de la actitud diabólica, inhumana, de su inquilino jorobado. La vampírica parafilia que empuja al organista a matar a mujeres, el comportamiento enloquecido y cruel del Jerónimo, los celos enfermizos de Harry hacia su hermana y el amor perturbador de la baronesa hacia el cadáver de su hija «ahonda[n] en lo prohibido, en lo tabú, para reflexionar sobre la maldad más plausible y manifiesta, la que nace en el hombre mismo» (López Santana, 2010: 239). 


\section{CONCLUSIONES}

El análisis de Villa del Mar y de El caserón del órgano revela la estrecha relación que algunas novelas policiacas de quiosco mantenían con el terror durante el primer periodo del franquismo. El empleo en las obras estudiadas de rasgos idiosincráticos de este subgénero intensifica el sentimiento de peligro en el lector, proporcionando así una acción más trepidante, acorde con los gustos populares de estos años. Tanto los personajes como los espacios en los que se desarrolla la trama remiten a la narrativa de quiosco que explotó, en ocasiones hasta el agotamiento, los tópicos que esta literatura presentaba. El entretenimiento se basa, por tanto, en una aventura constante en la que los detectives se comportan como héroes que, sin necesidad de recurrir a sus capacidades intelectuales y enfrentándose a diversos peligros, descubren al criminal gracias al espionaje llevado a cabo sobre los sospechosos. Estos, acorralados por distintas evidencias, reconocen su culpabilidad y esclarecen lo ocurrido en una confesión, obtenida a veces a través de métodos un tanto violentos.

Asimismo, el terror, que en estos casos se manifiesta de modo evidente en varios de los escenarios en los que se desarrollan las tramas y en el carácter sospechoso de distintos personajes, tiende a lo irracional por lo perturbador de los crímenes descritos. La necesaria localización de la historia en ciudades extranjeras posibilita la recreación de temas que, situados en España, resultaban intolerables para la estricta moral defendida por la censura de la época. Con estas tramas truculentas se resalta el lado oscuro del ser humano, su crueldad y la maldad que en ocasiones alberga, dando lugar a fratricidios -que se producen en los dos textos- e incluso, en El caserón del órgano, a una peculiar parafilia que, al igual que un ímpetu sexual, excita los instintos vampíricos de Federico Weldom y le proporciona placer al morder las sienes palpitantes de mujeres jóvenes.

De esta manera, los peligros que encuentran los protagonistas a lo largo del texto, así como los hechos en principio inexplicables que suponen también un riesgo para sus vidas, mantienen en tensión al lector y favorecen que este sienta de un modo más cercano esas amenazas a las que los detectives se enfrentan. A ello contribuye de igual modo el planteamiento de algunos enigmas secundarios que complican aún más la investigación y dificultan la labor policial. Así, en El caserón del órgano el detective busca indicios que resuelvan no solo el asesinato del notario Ángel Veragüas -relacionado a su vez con el robo de unas 
valiosas joyas-, sino también las muertes violentas y en extrañas circunstancias de mujeres vinculadas con Federico Weldom.

Con todo ello, Josefina de la Torre incursiona en el subgénero del terror adoptando sus tópicos y reproduciéndolos para conseguir el favor de ese lector que busca un rato de ocio que, sin duda, estas narraciones proporcionan. La autora, a pesar de ser incluida en los estudios filológicos actuales sobre todo por su obra lírica, demuestra así que los escritores considerados relevantes en determinados ámbitos literarios también sienten interés por esta literatura en gran medida desdeñada por los círculos académicos. Si bien el origen de estos textos surge de una necesidad económica, De la Torre exhibe una serie de personajes, de espacios y de desarrollos narrativos que evidencian que conocía y leía novelas de quiosco, hasta el punto de reproducir muchos de sus tópicos en las obras analizadas. Por tanto, se manifiesta la necesidad de estudiar esta narrativa para conseguir una visión más amplia y, al mismo tiempo, más precisa de las distintas facetas de Josefina de la Torre como escritora. 
BIBLIOGRAFÍA

Alemán Sainz, Francisco (1975): Las literaturas de kiosko, Barcelona, Planeta.

Álvarez Barrientos, Joaquín; María José Rodríguez Sánchez de León (1997): Diccionario de literatura popular española, Salamanca, Ediciones Colegio de España.

Amorós, Andrés (1974): Subliteraturas, Barcelona, Ariel.

Balló, Tània (2016): Las Sinsombrero. Sin ellas, la bistoria no está completa, Barcelona, Espasa.

Barreiro, Enrique (1969): «La novela de quiosco en España», en Revista española de la opinión pública, 17: 71-84.

Bellver, Catherine G. (2001): Absence and Presence. Spanish Women Poets of the Twenties and Thirties, Lewisburg, Pensilvania, Bucknell University Press.

Carrera Garrido, Miguel (2015): «El terror sí tiene forma: delimitación teórica de una categoría estética», en Natalia Álvarez Méndez y Ana Abello Verano (coords.), Espejismos de la realidad. Percepciones de lo insólito en la literatura española (siglos XIX-XXI), León, Servicio de Publicaciones de la Universidad de León: 75-84.

Carroll, Noël (1990): The Philosophy of Horror or Paradoxes of the Heart, Nueva York, Routledge.

Charlo, Ramón (2005): Autores y seudónimos en la novela popular, Sevilla, Padilla Libros Editores y Libreros.

Charlo Ortiz-Repiso, Ramón (2013): La novela popular en España, Sevilla, Secretariado de Publicaciones de la Universidad de Sevilla.

Checa, Edith (1997): Rincón literario. Homenaje a las mujeres de la Generación del 27. Josefina de la Torre, España, UNED TV: https://bit.ly/2Mgofqf (último acceso: 22/05/2019).

Colmeiro, José F. (1994): La novela policiaca española: teoría e historia crítica, Barcelona, Anthropos.

De la Torre, Josefina (1941): Villa del Mar, Madrid, Gráficas Uguina.

De la Torre, Josefina (1944): El caserón del órgano, Madrid, Ediciones Océano.

De Santiago Mulas, Vicente (2002): Historia externa de la novela criminal en España (1939-1975), Madrid, Universidad Complutense de Madrid: https://bit.ly/2JAkL4G (último acceso: 22/05/2019).

Díez Borque, José María (1972): Literatura y cultura de masas. Estudio de la novela subliteraria, Madrid, Al-Borak.

Durán, Javier (2008): «El rescate de Josefina de la Torre», en Moralia. Revista de estudios modernistas, 7: 85-89: https://bit.ly/2HvD0FY (22/05/2019). 
Eguidazu, Fernando (2008), Del folletín al bolsilibro. 50 años de novela popular española (1900-1950), Guadalajara, Silente.

Gallo Soler, Miguel (2016): «Novela rosa y fantasía amorosa en la España de los años cuarenta: análisis de La rival de Julieta de Josefina de la Torre», en Cuadernos de Aleph, 8: 128-148: https://bit.ly/2VGbwl9 (último acceso: 22/05/2019).

Godsland, Shelley (2007): Killing Carmens. Women's Crime Fiction from Spain, Wiltshire, University of Wales Press.

Gómez Rivero, Ángel (2007): Casas malditas. La arquitectura del horror, Madrid, Calamar Ediciones.

Hernández Quintana, Blanca (2001): «Josefina de la Torre Millares, una escritora vanguardista», en El Guiniguada. Revista de Investigaciones y Experiencias en Ciencias de la Educación, 10: 45-56: https://bit.ly/2WhCJ1S (último acceso: 22/05/2019).

López Santana, Miriam (2010): La novela gótica en España (1788-1833), Vigo, Academia del Hispanismo.

Martín Cerezo, Iván (2006), Poética del relato policiaco (de Edgar Allan Poe a Raymond Chandler), Murcia, Servicio de Publicaciones de la Universidad de Murcia.

Martín Fumero, José Manuel (2011): Las otras voces de la lírica insular de vanguardia (Julio Antonio de la Rosa, José Rodriguez. Batllori, Josefina de la Torre, Félix Delgado, José Antonio Rojas, Agustin Miranda Junco e Ismael Dominguez), San Cristóbal de La Laguna, Servicio de Publicaciones de la Universidad de La Laguna.

Martín Fumero, José Manuel (2019): «En el cuerpo textual de las dos ediciones de Marzo incompleto, de Josefina de la Torre», en Castilla. Estudios de Literatura, 10: 584-622: https://bit.ly/2QfFxqN (último acceso: 22/05/2019).

Martín Padilla, Kenia (2015a): «Josefina de la Torre o la versatilidad imperdonable», en Fogal, 6: https://bit.ly/2UtUmq7 (último acceso: 22/05/2019).

Martín Padilla, Kenia (2015b): «Josefina de la Torre: perfil polifacético», en Revista Digital Cuatrimestral de la Academia Canaria de la Lengua, 4: https:/ / bit.ly/2VEKKt5 (último acceso: 22/05/2019).

Martín Padilla, Kenia (2015c): «Josefina de la Torre: en memoria de una estrella», en Nexo, 12: 13-20: https://bit.ly/2XviLgV (último acceso: 22/05/2019).

Mederos, Alicia (1999): «Josefina de la Torre: "la poesía sigue pareciéndome inexplicable”», Anarda siglo XXI. Revista de Canarias, 7: 45-46.

Mederos, Alicia (2008): «Entre Modernismo y Vanguardia», en Javier Durán Angulo (dir.) y 
Cecilia Salerno (coord.), La última voz del 27: actas del Seminario Josefina de la Torre Millares, Las Palmas de Gran Canaria, Consejería de Educación, Universidades, Cultura y Deportes, Viceconsejería de Cultura y Deportes: 13-17.

Millares, Selena (2008): «Órbita literaria de Josefina de la Torre: Una poeta entre dos generaciones», en Javier Durán Angulo (dir.) y Cecilia Salerno (coord.), La última voz del 27: actas del Seminario Josefina de la Torre Millares, Las Palmas de Gran Canaria, Consejería de Educación, Universidades, Cultura y Deportes, Viceconsejería de Cultura y Deportes: 59-88.

Morales, Silvia (1943): «Una visita a Josefina de la Torre», en Primer Plano, 157: 7-8.

Porter, Dennis (1983): The Pursuit of Crime. Art and Ideology in Detective Fiction, New Haven, Yale University Press.

Reverón Alfonso, Juan Manuel (2007): Vida y obra de Claudio de la Torre, Santa Cruz de Tenerife, Ediciones Idea.

Reyes, Carlos (2000): «Introduction» en Josefina de la Torre: Poemas de la Isla, Washington, EE.UU., Eastern Washington University: 11-23.

Reyes, Carlos (2001): «Introducción» en Josefina de la Torre: Hojas sueltas / Scattered Leaves, Portland (Oregon), Trask House Books: 7.

Romero-López, Dolores; José Luis Bueren Gómez-Acebo (2019): «La colección Literatura de Quiosco en Mnemosine, Biblioteca Digital de la Otra Edad de Plata (1868-1936): hacia la redefinición del canon literario a través de metadatos», en Literatura: teoría, historia, crítica, 21, 1: 61-91: https://bit.ly/2EnQNfO (último acceso: 22/05/2019).

Rueda Laffond, José Carlos (2015): «Las colecciones populares: literatura de quiosco y tebeos», en Jesús Antonio Martínez Martín (coord.), Historia de la edición en España (1939-1975), Madrid, Marcial Pons Historia: 659-679.

Ryker, Alessandro (2008): «Josefina de la Torre y las mujeres así», en Javier Durán Angulo (dir.) y Cecilia Salerno (coord.), La última voz del 27: actas del Seminario Josefina de la Torre Millares, Las Palmas de Gran Canaria, Consejería de Educación, Universidades, Cultura y Deportes, Viceconsejería de Cultura y Deportes: 241-246.

Sánchez Zapatero, Javier (2006): «Apuntes para una perspectiva histórica del policiaco español», en Álex Martín Escribá y Javier Sánchez Zapatero (coords.), Manuscrito criminal. Reflexiones sobre novela y cine negro, Salamanca, Librería Cervantes: 69-84.

Sánchez Zapatero, Javier; Álex Martín Escribá (2011): «Del quiosco al best-seller. la novela policiaca en España», en Ana Cabello (coord.), Aproximaciones a la literatura populary 
de masas escrita en español (siglos XX y XXI), Madrid, Los libros de la Catarata: 93-108.

Santana, Lázaro (1989): "Introducción” en Lázaro Santana (ed.), Poemas de la isla, Madrid, Viceconsejería de Cultura y Deportes del Gobierno de Canarias: 9-21.

Spang, Kurt (2000 [1993]): Géneros literarios, Madrid, Síntesis.

Tarancón Gimeno, Jorge (2001): «Catálogo de la novela popular española», en VV.AA., La novela popular en España 2, Madrid, Ediciones Robel: 307-359.

Utrera Macías, Rafael (2008): «Mujeres “cineastas” de la Generación del 27. Josefina de la Torre: Arlette en la marisma», en Javier Durán Angulo (dir.) y Cecilia Salerno (coord.), La última voz. del 27: actas del Seminario Josefina de la Torre Millares, Las Palmas de Gran Canaria, Consejería de Educación, Universidades, Cultura y Deportes, Viceconsejería de Cultura y Deportes: 227-240.

Valles Calatrava, José R. (1991): La novela criminal española, Granada, Servicio de Publicaciones de la Universidad de Granada.

Vázquez de Parga. Salvador (1993): La novela policíaca en España, Barcelona, Ronsel.

Vázquez de Parga, Salvador (2000): Héroes y enamoradas. La novela popular española, Barcelona, Glénat.

Vázquez Montalbán, Manuel (1989): «Sobre la inexistencia de la novela policiaca en España», en Juan Paredes Núñez (ed.), La novela policiaca española, Granada, Universidad de Granada: 49-62.

Vosburg, Nancy (2011): «Spanish Women’s Crimen Fiction, 1980s-2000s: Subverting the Conventions of Genre and Gender», en Nancy Vosburg (ed.), Iberian Crime Fiction, Wiltshire, University of Wales Press: 75-92. 
SOBRE LA AUTORA

\section{Alberto García-Aguilar}

Graduado en Español: Lengua y Literatura por la Universidad de La Laguna, cuenta con un máster en Literatura Española e Hispanoamericana, Teoría de la Literatura y Literatura Comparada por la Universidad de Salamanca. Actualmente desarrolla su tesis doctoral en el programa de Arte y Humanidades de la Universidad de La Laguna con una ayuda a la formación de personal investigador predoctoral concedida por la Agencia Canaria de Investigación, Innovación y Sociedad de la Información del Gobierno de Canarias.

Contact information: agarciaa@ull.edu.es 